\title{
Obesity and the Metabolic Response to Severe Multiple Trauma in Man
}

Malayappa Jeevanandam, David H. Young, and William R. Schiller

Trauma Center, St. Joseph's Hospital and Medical Center, Phoenix, Arizona 85013

\begin{abstract}
In the obese state profound metabolic disturbances exist and it is not known how this disrupted metabolism in obese subjects (body mass index $>30$ ) may change their ability to respond to the superimposed, injury-induced stress. Understanding the mechanisms that modify the metabolic parameters in traumatized obese patients is essential in their nutritional assessment and further treatment. We have investigated in 7 obese and 10 nonobese multiple trauma patients, on a whole-body level, the energy metabolism, protein kinetics, and lipolysis in the early catabolic "flow phase" of severe injury when they were receiving maintenance fluids without calories or nitrogen. Traumatized obese patients mobilized relatively more protein and less fat compared with nonobese subjects. A relative block both in lipolysis and fat oxidation is experienced by injured obese patients that results in a shift to preferential use of proteins and carbohydrates. Reduced endogenous protein synthetic efficiency observed in obese patients implies increased protein recycling. Thus obese patients could not effectively use their most abundant fat fuel sources and have to depend on other fuel sources. The nutritional management of obese trauma victims should therefore be tailored towards provision of enough glucose calories to spare protein. (J. Clin. Invest. 1991. 87:262269.) Key words: protein kinetics - energy and trauma meta-
\end{abstract} bolic response $\bullet$ injury effects acute trauma

\section{Introduction}

Obesity is a metabolic and nutritional disorder and its cause in humans may be hereditary or acquired. A person with body mass index (BMI) $)^{1}$ of 30 or above, which is equal to about $30 \%$ over ideal body weight (IBW) is considered obese. Profound

This work was presented in part at the 14th Clinical Congress of American Society for Parenteral and Enteral Nutrition, San Antonio, TX, 28-31 January 1990, and published in abstract form 1990 (J. Parenter. Enteral Nutr. 14:128).

Address reprint requests to Dr. M. Jeevanandam, Trauma Center, St. Joseph's Hospital \& Medical Center, 350 West Thomas Road, Phoenix, AZ 85013. 1990.

Received for publication 2 March 1990 and in revised form 15 June

1. Abbreviations used in this paper: APE, atom percent excess; BMI, body mass index; FFA, free fatty acids; LBM, lean body mass; NCO, net carbohydrate oxidation; NFO, net fat oxidation; NPO, net protein oxidation; PSE, protein synthesis efficiency; REE, resting energy expenditure; $R Q$, respiratory quotient; TBF, total body fat mass; TG, triglycerides; $3 \mathrm{MH}, 3$ methylhistidine; $V_{\mathrm{CO}_{2}}$, carbon dioxide production; $V_{\mathrm{O}_{2}}$, oxygen consumption; WBLR, whole-body lipolysis rate; WBPT, whole-body protein turnover.

\footnotetext{
J. Clin. Invest.

(C) The American Society for Clinical Investigation, Inc.

$0021-9738 / 91 / 01 / 0262 / 08 \quad \$ 2.00$

Volume 87, January 1991, 262-269
}

metabolic disturbances exist in the obese state that constantly interfere with normal hormonal responses. Glucose intolerance, insulin insensitivity, and hypertension are common in obese patients who are clinically prone to diabetes, respiratory complications, and cardiovascular-renal diseases (1). Obese subjects have increased resting energy expenditure (REE) compared with lean subjects in absolute terms and an increased lean body mass (LBM) accounts for the high REE (2). Compared to fasting normal-weight subjects, fasting obese subjects generally have increased levels of plasma components including substrates, amino acids, and hormones $(1,3,4)$. It is not known how this disrupted metabolism in obesity may respond when subjected to injury-induced stress. Systematic investigation of the altered biological mechanisms in severely injured obese patients has not been attempted previously.

The incidence of surgical complications has been reported as increased in obese patients $(5,6)$. Although obesity is commonly considered a surgical risk factor, the degree of risk has not been identified (7). The catabolic phase after accidental injury is inevitable and one of the dominant factors in this phase is the increased release of free fatty acids (FFA) during increased lipolysis. Fat mobilization itself is probably not harmful if protein mass can be protected. The metabolic machinery in obese but otherwise healthy subjects is already altered due to increased glucose and insulin productions with augmented lipolysis and utilization of the lipolytic products ( 1 , 4). Understanding how injury-induced stress further alters these parameters in obese patients is essential in the nutritional assessment and treatment of traumatized patients.

The objectives of this study are to examine, on a wholebody level, the energy and protein metabolism during the catabolic "flow phase" of acute trauma in obese subjects compared with equally injured nonobese subjects.

\section{Methods}

\section{Patients}

17 adult multiple trauma patients ( 7 obese, BMI $>30$, and 10 nonobese, BMI < 30) were studied after admission to the Intensive Care Unit of the Level I Trauma Center at St. Joseph's Hospital and Medical Center in Phoenix, Arizona. The protocol for this study was approved by the Medical Research Committee. Table I summarizes the characteristics of the two groups of patients. Written consent was obtained from the patient or legal guardian before initiating the study. All patients were studied within 2 to $4 \mathrm{~d}$ of major injury when they were receiving maintenance fluid and electrolytes but without calories or nitrogen.

At the time of study, none of the patients were septic, had multiple organ failure, diabetes, recent weight loss, or liver, renal, or malignant disease. Injuries were scored according to injury severity score (ISS) based upon the abbreviated injury score (AIS) of the three most serious injuries (8). All had at least one major injury and multiple minor injuries with ISS ranging from 18 to 50 . The patients were evaluated and resuscitated according to individual needs as determined by the trauma team. All of the patients required ventilatory support during this period. 
Table I. Patient Characteristics

\begin{tabular}{|c|c|c|c|c|c|c|c|c|c|c|}
\hline \multirow[t]{2}{*}{ Patient } & \multirow[t]{2}{*}{ Sex } & \multirow{2}{*}{$\frac{\text { Age }}{y r}$} & \multicolumn{2}{|c|}{ Body weight } & \multirow{2}{*}{$\begin{array}{c}\text { LBG } \\
k g\end{array}$} & \multirow{2}{*}{$\begin{array}{c}\text { TBF } \\
k g\end{array}$} & \multirow{2}{*}{$\begin{array}{c}\text { BMI } \\
k g / m^{2}\end{array}$} & \multirow[t]{2}{*}{ ISS } & \multirow[t]{2}{*}{$\begin{array}{c}\text { REE } \\
\text { (\%BEE) }\end{array}$} & \multirow{2}{*}{$\frac{N \text { loss }}{g N / d}$} \\
\hline & & & $k g$ & $\% I B W$ & & & & & & \\
\hline \multicolumn{11}{|c|}{ A Obese patients } \\
\hline $0-1$ & $\mathbf{M}$ & 25 & 122.2 & 160 & 69.2 & 53.0 & 36.5 & 25 & - & 32.5 \\
\hline $\mathrm{O}-2$ & $\mathbf{F}$ & 65 & 82.7 & 163 & 46.8 & 35.9 & 34.3 & 17 & 132 & 13.9 \\
\hline $0-3$ & $\mathbf{M}$ & 32 & 119.0 & 180 & 67.4 & 51.6 & 40.9 & 30 & 170 & 29.8 \\
\hline $0-4$ & $\mathbf{M}$ & 27 & 99.8 & 135 & 56.5 & 43.3 & 30.8 & 18 & 115 & 29.9 \\
\hline $0-5$ & $\mathbf{F}$ & 51 & 90.7 & 199 & 51.3 & 39.4 & 41.8 & 34 & 135 & 11.0 \\
\hline $0-6$ & $\mathbf{M}$ & 57 & 113.9 & 156 & 64.5 & 49.4 & 35.5 & 34 & - & 20.4 \\
\hline O-7 & F & 66 & 95.5 & 161 & 54.1 & 41.4 & 33.8 & 29 & 148 & 18.2 \\
\hline Mean (7) & $4 \mathrm{M} / 3 \mathrm{~F}$ & 46.1 & 103.4 & 165 & 58.5 & 44.9 & 36.2 & 27 & 140 & 22.2 \\
\hline \pm SEM & & 6.7 & 5.7 & 8 & 3.2 & 2.5 & 1.5 & 3 & 9 & 3.2 \\
\hline \multicolumn{11}{|c|}{ B Nonobese patients } \\
\hline NO-1 & $\mathbf{M}$ & 74 & 65.8 & 88 & 54.9 & 10.9 & 20.1 & 17 & 134 & 12.7 \\
\hline NO-2 & $\mathbf{F}$ & 46 & 81.5 & 120 & 68.1 & 13.4 & 26.6 & 22 & 163 & 12.6 \\
\hline NO-3 & $\mathbf{M}$ & 24 & 86.2 & 116 & 72.0 & 14.2 & 26.5 & 20 & 151 & 18.6 \\
\hline NO-4 & $\mathbf{F}$ & 25 & 59.3 & 100 & 49.5 & 9.8 & 21.1 & 26 & 117 & 7.4 \\
\hline NO-5 & $\mathbf{M}$ & 18 & 78.9 & 123 & 65.9 & 13.0 & 28.3 & 50 & 140 & 21.8 \\
\hline NO-6 & $\mathbf{M}$ & 25 & 91.6 & 119 & 76.5 & 15.1 & 27.3 & 38 & 140 & 19.3 \\
\hline NO-7 & $\mathbf{M}$ & 69 & 80.1 & 102 & 66.9 & 13.2 & 23.3 & 18 & 164 & 14.8 \\
\hline NO-8 & $\mathbf{F}$ & 21 & 79.2 & 122 & 66.1 & 13.1 & 25.7 & 45 & 152 & 9.1 \\
\hline NO-9 & $\mathbf{F}$ & 20 & 59.0 & 106 & 49.3 & 9.7 & 22.3 & 40 & 175 & 7.7 \\
\hline NO-10 & $\mathbf{M}$ & 60 & 96.6 & 121 & 80.7 & 15.9 & 28.8 & 22 & 136 & 18.8 \\
\hline Mean (10) & $6 \mathrm{M} / 4 \mathrm{~F}$ & 38.2 & 77.8 & 111 & 65.0 & 12.8 & 25.0 & 28 & 137 & 14.3 \\
\hline \pm SEM & & 7.0 & 4.1 & 4 & 3.4 & 0.7 & 1.0 & 5 & 14 & 1.7 \\
\hline
\end{tabular}

IBW, Ideal body weight; BMI, body mass index; LBM, lean body mass (kg); TBF, total body fat (kg); LBM and TBF are based on the estimation (Ref. 24,25 ) that obese subjects have $43.4 \%$ of their body weight as fat and nonobese subjects $16.5 \%$. ISS, injury severity score; REE, resting energy expenditure; BEE, basal energy expenditure (predicted by Harris-Benedict equation).

\section{Study protocol}

Patients were started on maintenance fluid intravenously upon entering the protocol. 24-h urine collections through a Foley catheter were initiated and continued until the end of the study. When the medical status of the patients was stable and resuscitation complete, they were weighed and blood samples were drawn in the morning through an existing arterial line for basal substrate and hormone measurements. This occurred 48-72 $\mathrm{h}$ after injury during the early stage of the flow phase of the metabolic response to injury.

A venous catheter was inserted in an arm vein for withdrawing timed blood samples. Oxygen consumption $\left(V_{\mathrm{O}_{2}}\right)$, carbon dioxide production $\left(V_{\mathrm{CO}_{2}}\right)$, and respiratory quotient $(R Q)$ were measured using the metabolic cart (Horizon Metabolic Measurement Cart; Sensormedics, Corporation, Anaheim, CA). The metabolic cart was calibrated before each measurement and the stability of the instrument conditions was observed for at least a 10-min equilibration period. The test measurement was performed over a 20 -min period of continuous sampling. 1-min averages of $V_{\mathrm{O}_{2}}, V_{\mathrm{CO}_{2}}$, and $R Q$ were printed. Means of $V_{\mathrm{O}_{2}}$ and $V_{\mathrm{CO}_{2}}$ during the 20-min period along with the urinary total nitrogen excretion were used to calculate the REE and substrate oxidation rates $(9,10)$. Predicted basal energy expenditure (BEE) was calculated by the appropriate Harris-Benedict equation, taking into consideration the age, gender, height, and weight (11).

A two-stage primed-constant infusion of glycerol $(10 \% \mathrm{wt} / \mathrm{wt})$ was used to measure the glycerol turnover rate (12). The net rate of glycerol turnover in plasma reflects the net unidirectional breakdown of body lipid stores and hence an assessment of whole-body lipolysis rate (WBLR) $(12,13)$. A $10 \%$ solution of glycerol in normal saline was prepared, ultra-filtered, and pyrogen-tested. Using an infusion pump (IMED Corporation, San Diego, CA), the two-stage glycerol infusion was started with each 70-min stage primed with a dose of $2 \mathrm{mmol}$ glycerol and an infusion of 250 and $500 \mu \mathrm{mol} / \mathrm{min}$. During the last 10 min of each stage, three blood samples ( $3 \mathrm{ml}$ each) were drawn using heparinized syringes at equal intervals. All samples were immediately placed on melting ice and centrifuged in the cold. Plasma $(0.5 \mathrm{ml}$ in duplicate) was pipetted into $0.5 \mathrm{ml}$ of $10 \%$ perchloric acid, mixed, centrifuged, and the supernatant was analyzed immediately for glycerol or stored at $-80^{\circ} \mathrm{C}$ for analysis within a week.

At the end of the lipid kinetic study, the whole-body protein turnover (WBPT) measurement was started. It was determined by administration of an initial dose of $\left[{ }^{15} \mathrm{~N}\right]$ glycine followed by a continuous infusion for $24 \mathrm{~h}$ and separate measurements of isotope excretion in urinary urea and ammonia (14). Before the isotope study, a urine sample was obtained for the measurement of baseline enrichment of ${ }^{15} \mathrm{~N}$ in urea and ammonia. No subject was allowed any nutrient during the study. The venous catheter placed in the forearm was used for isotope infusion.

$\left[{ }^{15} \mathrm{~N}\right]$ Glycine (99 atom \%; Tracer Technologies, Inc., Newton, MA) was dissolved in saline solution, sterilized by filtration (Millipore/Continental Water Systems, Bedford, MA) and tested for pyrogenicity and sterility. An initial booster dose of $0.45 \mathrm{mg}{ }^{15} \mathrm{~N} / \mathrm{kg}\left(2.26 \mathrm{mg}{ }^{15} \mathrm{~N}\right.$ glycine/kg) was administered intravenously, followed by continuous infu-

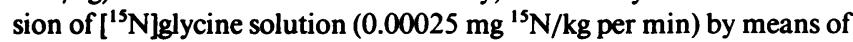
a volumetric infusion pump (IMED) at the rate of $20 \mathrm{ml} / \mathrm{h}$ for $24 \mathrm{~h}$. The prime to infusion ratio was $1,800: 1$. This prime dose is similar to that given in single dose studies in humans and corresponds to $\sim 8 \%$ of 
the body glycine pool. The infusion rate amounts to $\sim 0.3 \%$ of the body glycine flux and these rates of dose administration should not affect basal metabolism. Urine was collected at 12, 16, 18, 20,22, and 24-h periods. Samples of urine were processed and stored at $-20^{\circ} \mathrm{C}$ before analysis.

\section{Analytical methods}

The biochemical profile in the blood samples was performed using automated procedures. Plasma levels of glucose, blood urea nitrogen (BUN), triglycerides (TG), FFA, ketone bodies, glycerol, and creatinine were determined using standard procedures in a centrifugal analyzer (IL Multistat Plus III; Instrumentation Laboratories, Inc., Lexington, MA). Using an amino acid analyzer (model 7300; Beckman Instruments, Inc., Palo Alto, CA), 3 methylhistidine (3MH) in the urine was measured. Commercial RIA kits (Diagnostic Products Corp., Los Angeles, CA) were used to determine plasma insulin, glucagon, cortisol and C-peptide. Levels of norepinephrine and epinephrine were measured by HPLC column separation and electro-chemical detection (Bioanalytical Systems, Inc., W. Lafayette, IN).

A $10 \%$ aliquot of each urine sample collected during the isotope infusion was pooled to represent a 24-h sample. The total nitrogen in urine was measured with a Chemiluminescence digital analyzer (Antek Instruments, Inc., Houston, TX). Urinary ammonia was isolated by adding saturated potassium carbonate to a $5-\mathrm{ml}$ aliquot of urine and absorbing the evolved ammonia in $1 \mathrm{ml}$ of $1 \mathrm{~N}$ sulfuric acid. A simplified routine method (15) for the estimation of ${ }^{15} \mathrm{~N}$ atom percentage in urinary urea was used by removing the ammonia from urine by shaking with Permutit resin and then treating with sodium hypobromite for mass spectrometric analysis of nitrogen.

For measurement of ${ }^{15} \mathrm{~N}$, samples containing ammonium ions or Permutit-treated urine were allowed to react with aged sodium hypobromite in an evacuated Rittenberg tube to liberate nitrogen gas (14). Quantitative measurement of ${ }^{15} \mathrm{~N}$ was determined in a $60^{\circ}$-Nier type, dual collector isotope-ratio-mass spectrometer that was capable of giving a precision of 2 parts per 100,000. All samples were analyzed in duplicate and the coefficient of variation during multiple analyses of a sample was $<0.5 \%$. The atom percentage of ${ }^{15} \mathrm{~N}$ (AP) in each sample was calculated from the mass 28 and 29 peak heights after correction for instrument background. The atom percentage excess (APE) of each study sample was obtained by subtracting the AP of urea or ammonia ${ }^{15} \mathrm{~N}$ in the control sample taken before isotopic administration. The steady-state plateau values in urea and ammonia were reached in 16$20 \mathrm{~h}$ as observed previously in other pathological conditions (14).

\section{Calculation}

Whole-body lipolysis rate. The glycerol turnover $(\mu \mathrm{mol} / \mathrm{min})$ was calculated by multiplying the basal glycerol concentration by clearance (9). This technique had been used successfully before in normal and many pathological states $(12,13,16)$. The clearance at each stage was obtained by dividing the change in infusion rate by the change in concentration and then averaged. At each stage the glycerol concentration of samples taken at 60,65 , and $70 \mathrm{~min}$ did not change by $>3 \%$. The clearance rate was found to be constant over this plasma concentration.

The turnover rate of $1 \mathrm{~mol}$ of glycerol is associated with mobilization of $1 \mathrm{~mol}$ of TG from fat stores, hence the WBLR, kcal/d, was obtained by multiplying glycerol turnover $(\mu \mathrm{mol} / \mathrm{min})$ by a factor of 11.726. In this calculation dioleyl-palmityl triglyceride (mol wt $=895.5 ; 1 \mathrm{~mol} \mathrm{TG}=8,143 \mathrm{kcal}$ ) is considered to be representative of TG from human fat stores (13). The amount of energy derived from net fat oxidation (NFO) was calculated from indirect calorimetry measurements and the difference between this value and the energy mobilized from fat stores (WBLR) was taken to represent the energy recycled back to TG by reesterification of fatty acids (13). The energy cost of TG/FFA cycling can be calculated by assuming that $8 \mathrm{~mol}$ ATP were utilized for each mole of TG recycled and that the energy equivalent of 1 mol ATP is $19.1 \mathrm{kcal}(13,17)$.

Rates of protein dynamics. The turnover rate $(Q)$ is defined as the rate of flow of nitrogen into or out of the metabolic pool under steady- state conditions and is calculated by dividing the isotope infusion rate, $I\left(\mathrm{mg}^{15} \mathrm{~N} / \mathrm{min}\right)$ by the plateau ${ }^{15} \mathrm{~N}$ APE in the urinary end product (14). The limitations of the assumptions and the validation of this technique have been reviewed $(18,19)$. The steady-state plateau values of APE in urea were found to be lower than those seen in ammonia. Since their relative contributions to the calculation of WBPT are not clearly established, it was proposed that the average of the two estimates, reflecting both liver and muscle pools of precursor mixtures, might be the most useful measure of WBPT (19-21). We have calculated WBPT using the average of the plateau APE in urea and ammonia.

Rates of protein synthesis and breakdown in the whole body under steady-state conditions were then determined from the expression $Q$ $=C+I N=S+E x$ where $C$ and $S$ are the rates of protein breakdown and synthesis, respectively, $I N$ is the rate of intake of nitrogen from the diet, and $E x$ is the rate of excretion of total nitrogen in urine. In this study there is no intake of nitrogen and the flux of $N$ entering the metabolic pool originates mainly from the breakdown of body proteins; hence $Q=C$. Some fraction of this flux $(S / Q)$ will be utilized in protein synthesis and the rest presumably metabolized and excreted in the urine (15). This used fraction (or percentage) is defined as protein synthesis efficiency (PSE) of endogenous origin, and therefore PSE $=S / Q$.

All WBPT units are expressed as grams of protein per day. A factor of 6.25 was used to convert grams of nitrogen into grams of protein. Nitrogen balance was calculated from the daily urinary $\mathrm{N}$ loss since there is no intake of $\mathrm{N}$ and no fecal output. For dermal and miscellaneous $\mathrm{N}$ losses, a value of $7 \mathrm{mg} / \mathrm{kg}$ per day was added to the output (22).

The values are reported as mean \pm SEM. Significances of differences between variables were calculated with Student's $t$ test (23) and the correlations were calculated by linear regression. Wilcoxon sum rank test (two tailed) was used to calculate the significances of PSE between groups. A $P$ value of 0.05 or less was considered significant.

\section{Results}

Table I summarizes the patient data on admission. These two groups of polytrauma victims had similar high ISS and resting energy expenditure. These hypermetabolic patients were also catabolic with a large daily $\mathrm{N}$ loss. The obese patients weighed $65 \%$ above ideal body weight. For a better comparison the kinetic data are expressed both as a function of LBM to assess the relationship between lipolysis and the physiological requirement for energy substrates and as a function of the total body fat mass (TBF) to indicate the responsiveness or sensitivity of the adipose tissue. The reported LBM and TBF values are based on the estimation that obese subjects have $43.4 \%$ of their body weight as fat and nonobese subjects $16.5 \%(24,25)$.

Fasting plasma levels of circulating substrates are given in Table II. Both the groups were hyperglycemic and the hypoalbuminemia due to injury was more pronounced in obese subjects. This may be a consequence of increased catabolism and/ or reduction in albumin synthesis, together with a change in the compartmentalization of body albumin $(26,27)$. Altered parameters of lipid metabolism due to injury were evident from the plasma levels of ketones, TG, FFA, and glycerol. A significant increase in FFA and decrease in glycerol levels were seen in obese patients. Circulating levels of plasma hormones are given in Table III. Obese patients showed increased levels of insulin, glucagon, cortisol, and C-peptide, although the statistical significance level was attained only with C-peptide. There was a blunted catecholamine level in obese trauma patients.

Parameters of protein kinetics are summarized in Table IV and the individual patient data are plotted in Fig. 1. Obese patients as a group show an increase in WBPT (23\%) and synthesis rates $(9 \%)$ although not statistically significant in abso- 
Table II. Blood Chemistry of Trauma Patients

\begin{tabular}{|c|c|c|c|c|c|c|c|c|}
\hline Patient & Glucose & BUN & Albumin & Ketone & FFA & Glycerol & Lactate & $\begin{array}{c}\text { Total } \\
\text { protein }\end{array}$ \\
\hline & $m g / d l$ & $m g ~ N / d l$ & $g / d l$ & $\mu M$ & $\mu M$ & $\mu M$ & $m g / d l$ & $g / d l$ \\
\hline
\end{tabular}

A Obese patients

\begin{tabular}{|c|c|c|c|c|c|c|c|c|c|}
\hline $0-1$ & 115 & 12.0 & 2.6 & 151 & 47 & 68 & 11 & 3.7 & 110 \\
\hline $0-2$ & 179 & 10.2 & - & 873 & - & 48 & 13 & - & 85 \\
\hline $0-3$ & 107 & 20.0 & 2.6 & 227 & 494 & 36 & 10 & 5.2 & 176 \\
\hline $0-4$ & 83 & 15.8 & 2.1 & 1,281 & 663 & 49 & 7 & 3.8 & 252 \\
\hline $0-5$ & 123 & 6.1 & 2.5 & 557 & 804 & 71 & 10 & 4.0 & 136 \\
\hline $0-6$ & 209 & 15.1 & 3.2 & 252 & 957 & 95 & 16 & 5.7 & 65 \\
\hline O-7 & 158 & 17.1 & 2.5 & 93 & 636 & 118 & 39 & 4.2 & 121 \\
\hline$\overline{\mathbf{x}}(7)$ & 139 & 138 & 2.6 & 491 & 671 & 69 & 15 & 4.4 & 135 \\
\hline \pm SEM & 17 & 1.8 & 0.1 & 167 & 76 & 11 & 4 & 0.3 & 24 \\
\hline
\end{tabular}

B Nonobese patients

\begin{tabular}{|c|c|c|c|c|c|c|c|c|c|}
\hline NO-1 & 91 & 17 & - & 1,193 & 544 & 70 & 29 & - & 72 \\
\hline NO-2 & 139 & 8 & 2.8 & 1,743 & 476 & 169 & 8 & 4.1 & 222 \\
\hline NO-3 & 138 & 12 & - & 550 & 553 & 53 & 25 & - & 258 \\
\hline NO-4 & 128 & 7 & - & 292 & 367 & 97 & 6 & - & 67 \\
\hline NO-5 & 126 & 14 & 3.0 & 108 & 232 & 111 & 21 & 4.9 & 102 \\
\hline NO-6 & 126 & 18 & 3.1 & 485 & 291 & 107 & 13 & 4.6 & 134 \\
\hline NO-7 & 174 & 14 & - & - & 250 & 72 & 12 & - & 142 \\
\hline NO-8 & 110 & 6 & 3.4 & 1,346 & 422 & 132 & 10 & 5.3 & 115 \\
\hline NO-9 & 89 & 8 & 3.4 & 281 & - & 166 & 14 & 5.4 & 86 \\
\hline NO-10 & 84 & 17.0 & 3.4 & 873 & - & 48 & 13 & 5.4 & 183 \\
\hline$\overline{\mathbf{x}}(10)$ & 121 & 12.1 & 3.2 & 764 & 392 & 103 & 15 & 4.1 & 138 \\
\hline \pm SEM & 8.8 & 1.5 & 0.1 & 187 & 45 & 9 & 2 & 0.8 & 20 \\
\hline$P$ & NS & NS & 0.025 & NS & 0.005 & 0.05 & NS & NS & NS \\
\hline
\end{tabular}

lute values or when normalized to body weight. However, when expressed as a function of LBM they were significantly increased ( $40 \%$ and $22 \%$, respectively) in obese patients. PSE in nonobese trauma patients is comparable to that reported by us before (15). However, obese trauma patients show a significantly decreased (12\%; $P=0.025) \mathrm{PSE}$, increased (56\%; $P$ $=0.025)$ daily $\mathrm{N}$ loss, and increased $(38 \% ; P=0.025)$ daily 3 methylhistidine (3MH) excretion compared with equally injured nonobese patients. There is a significant positive correlation (Fig. 2, $r=0.78 ; P=0.001$ ) between the isotopically derived whole-body protein breakdown rate $(C)$ and daily $3 \mathrm{MH}$ excretion. Urinary creatinine output could be considered as a

Table III. Plasma Hormone Levels in Trauma Victims

\begin{tabular}{lcccc}
\hline & Obese & & Nonobese & \\
\cline { 2 - 3 } & $n=7$ & & $n=10$ & $P$ \\
\hline Insulin, $\mu I U / m l$ & $19.4 \pm 2.2$ & & $12.7 \pm 4.0$ & NS \\
Glucagon, $p g / m l$ & $166 \pm 26$ & & $110 \pm 15$ & NS \\
Cortisol, $\mu g / d l$ & $34.3 \pm 3.3$ & & $26.0 \pm 3.9$ & NS \\
C-peptide,,$n g / m l$ & $4.1 \pm 1.1$ & & $2.1 \pm 0.2$ & 0.05 \\
Norepinephrine, $p g / m l$ & $395 \pm 106$ & & $545 \pm 182$ & NS \\
Epinephrine, $p g / m l$ & $261 \pm 86$ & & $368 \pm 79$ & NS
\end{tabular}

Mean \pm SEM. measure of muscle mass. In obese fasting injured subjects mean daily creatinine excretion rate is $2,106 \pm 254 \mathrm{mg}$ and $1,620 \pm 150$ $\mathrm{mg}$ in nonobese patients. Each milligram of creatinine in humans corresponds to $17.7 \mathrm{~g}$ of muscle (28) and it can be calculated that the obese group would have $37.3 \pm 4.5 \mathrm{~kg}$ of muscle mass, which is $36 \%$ of body weight. Similarly, the nonobese group would have $28.7 \pm 2.7 \mathrm{~kg}$ of muscle mass which is also $36 \%$ body weight. Mean daily urinary $\mathrm{N}$ loss of $22.2 \mathrm{~g}$ in obese patients corresponds to $556 \mathrm{~g}$ of muscle which accounts for $1.5 \%$ erosion of the whole-body muscle mass. In nonobese patients $\mathrm{N}$ loss of $14.3 \mathrm{~g}$ per day corresponds to $357 \mathrm{~g}$ muscle and $1.2 \%$ erosion of the body muscle mass.

Variables in energy and lipid metabolism are summarized in Table $\mathrm{V}$. There is no significant difference in either REE or oxygen consumption between the obese and nonobese hypermetabolic trauma patients. However, the partition of the energy fuel's contribution to REE is significantly different as shown in Fig. 3. Net fat oxidation (NFO) accounts for $61 \pm 4 \%$ of the REE in nonobese patients and, surprisingly, in obese patients it is only $39 \pm 3 \%$ of the REE. Net carbohydrate oxidation (NCO) and net protein oxidation (NPO) rates are significantly $(P=0.025)$ higher in obese patients; NCO is $39 \pm 4 \%$ and $24 \pm 2 \%$, and NPO is $22 \pm 2 \%$ and $15 \pm 1 \%$ of the REE in obese and nonobese patients, respectively. Statistical significances of these energy data are amplified when expressed as a function of LBM or TBF. Lipolysis of TG stores results in FFA and glycerol, and the mobilized FFA will be either oxidized to $\mathrm{CO}_{2}$ or 
Table IV. Parameters of Protein Metabolism in Trauma Victims

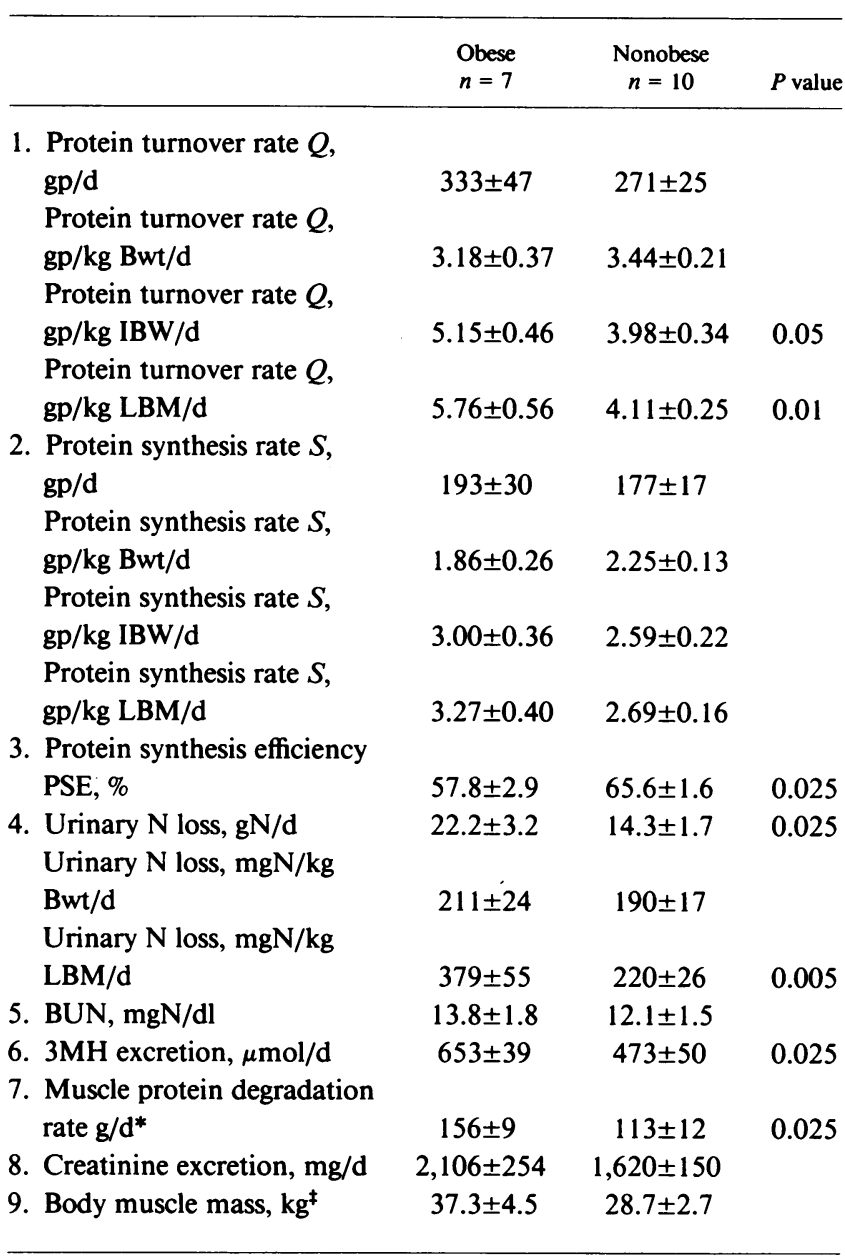

Mean \pm SEM

* From 3 methylhistidine excretion data.

${ }^{\ddagger}$ From creatinine excretion data.

used in the resynthesis of TG. Although the whole body lipolysis rate in absolute terms in obese patients is not statistically different from nonobese patients, the lipolysis per unit fat mass is significantly $(P=0.005)$ low in obese patients. The significantly lower level of plasma glycerol in obese patients is partly due to an increase $(26 \%)$ in clearance and a decrease $(24 \%)$ in turnover rate of glycerol. The higher level of plasma FFA seen in obese patients appears to indicate a block in the utilization of the FFA. In obese patients NFO accounts for $36 \pm 5 \%$ of the mobilized TG compared with $47 \pm 6 \%$ in nonobese patients (Fig. 4). The absolute value of the reesterification rate of the mobilized FFA is not different in the two groups of patients; however, the portion of the mobilized TG that is used in reesterification is higher $(64 \pm 5 \%)$ in obese patients compared with nonobese $(53 \pm 5 \%)$. The energy cost associated with cycling of FFA ( $34 \mathrm{kcal})$ is not different in the two groups of patients and accounts for $1.4 \%$ of REE.

\section{Discussion}

Major features of the posttraumatic response include enhanced metabolic rate, accelerated net protein breakdown, alterations of lipid and carbohydrate metabolism with associated changes

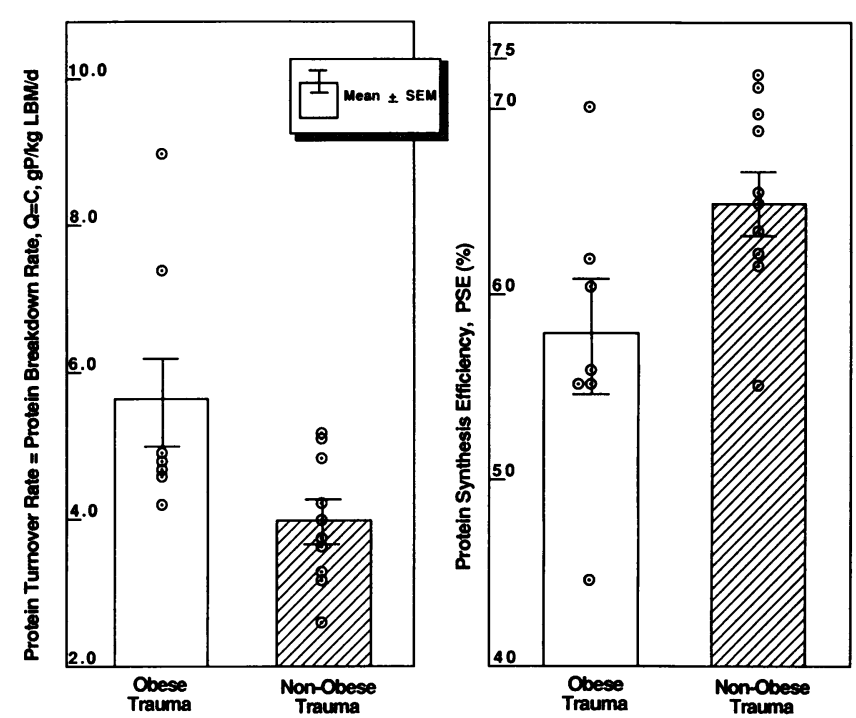

Figure 1. Protein turnover rate and protein synthesis efficiency in obese and nonobese patients.

in hormonal environment. The magnitude of these metabolic responses depends partly on the severity of injury and partly on the preinjury status of the patient. Acutely injured subjects with excessive body fat respond differently to the wound compared with normal weight victims. Accidents rank fourth as the principal causes of death among the overweight and only at a BMI of $>30$ did excess mortality become prominent (1). Contrary to the general belief that the most abundant supply of adipose tissues will be the primary fuel, the injured obese patients experience a relative block both in lipid mobilization and utilization. This leads to a shift in the mixture of fuel used resulting in a significantly increased oxidation rate of protein and carbohydrates in obese trauma patients compared with nonobese. Mobilization of protein sources is apparently accelerated mainly to provide substrates for the synthesis of glucose in the obese trauma victim.

Normal obese subjects are more efficient in conserving body nitrogen during a fast and they lose nitrogen as well as

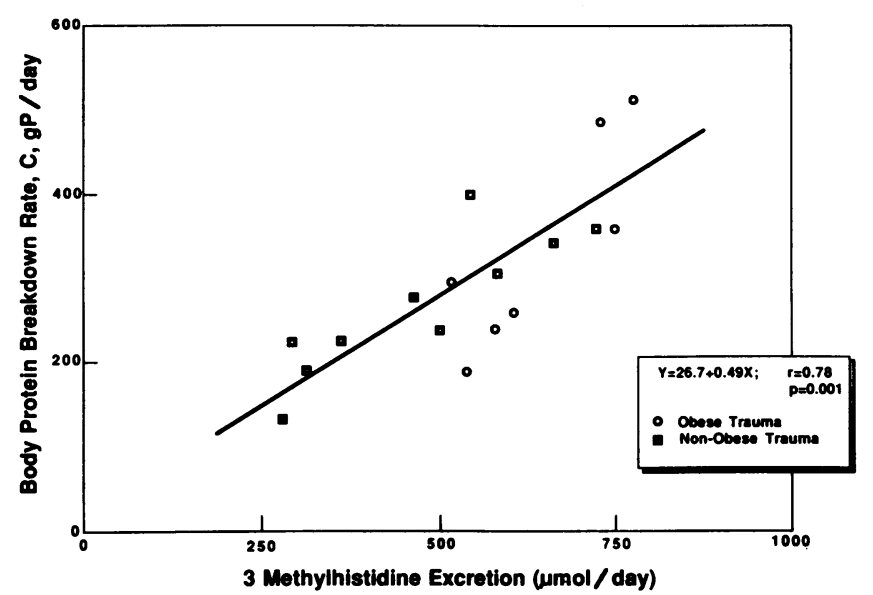

Figure 2. Linear correlation between whole-body protein breakdown rate $(Y)$ and daily 3 methylhistidine excretion $(X)$ in trauma victims. $Y=26.7+0.49 X ; r=0.78 ; P=0.001$. 


\begin{tabular}{|c|c|c|c|}
\hline & $\begin{array}{l}\text { Obese } \\
n=7\end{array}$ & $\begin{array}{c}\text { Nonobese } \\
n=11\end{array}$ & $\begin{array}{c}P \\
\text { value }\end{array}$ \\
\hline 1. Resting energy expenditure, REE, $\mathrm{kcal} / \mathrm{d}$ & $2,550 \pm 172$ & $2,538 \pm 162$ & - \\
\hline Resting energy expenditure, REE, $\mathrm{kcal} / \mathrm{kg} \mathrm{LBM} / \mathrm{d}$ & $43.6 \pm 2.9$ & $39.0 \pm 2.5$ & - \\
\hline Resting energy expenditure, REE, $k \mathrm{cal} / \mathrm{kg} \mathrm{TBF} / \mathrm{d}$ & $56.7 \pm 3.8$ & $198 \pm 12.6$ & 0.001 \\
\hline 2. Oxygen consumption, $\mathrm{ml} / \mathrm{min} / \mathrm{m}^{2}$ & $175 \pm 19$ & $206 \pm 14$ & - \\
\hline 3. Respiratory quotient, $R Q$ & $0.80 \pm 0.04$ & $0.80 \pm 0.02$ & - \\
\hline 4. Net fat oxidation, NFO, $k c a l / d r$ & $997 \pm 137$ & $1,560 \pm 160$ & 0.010 \\
\hline Net fat oxidation, NFO, \% REE & $39 \pm 3$ & $61 \pm 4$ & 0.001 \\
\hline Net fat oxidation, NFO, $\mathrm{kcal} / \mathrm{kg} \mathrm{LBM} / \mathrm{d}$ & $17.0 \pm 2.3$ & $24.0 \pm 2.1$ & 0.05 \\
\hline Net fat oxidation, NFO, $k c a l / k g r$ TBF/d & $22.2 \pm 3.1$ & $122 \pm 13$ & 0.001 \\
\hline 5. Net carbohydrate oxidation, NCO, $\mathrm{kcal} / \mathrm{d}$ & $986 \pm 83$ & $606 \pm 136$ & 0.050 \\
\hline Net carbohydrate oxidation, NCO, \% REE & $39 \pm 4$ & $24 \pm 2$ & 0.005 \\
\hline Net carbohydrate oxidation, NCO, $\mathrm{kcal} / \mathrm{kg} \mathrm{LBM} / \mathrm{d}$ & $16.9 \pm 1.4$ & $9.3 \pm 1.6$ & 0.005 \\
\hline Net carbohydrate oxidation, $\mathrm{NCO}, \mathrm{kcal} / \mathrm{kg} \mathrm{TBF} / \mathrm{d}$ & $21.9 \pm 1.8$ & $47.3 \pm 8.7$ & 0.025 \\
\hline 6. Net protein oxidation, NPO, $\mathrm{kcal} / \mathrm{d}$ & $570 \pm 68$ & $373 \pm 44$ & 0.025 \\
\hline Net protein oxidation, NPO, \% REE & $22 \pm 2$ & $15 \pm 1$ & 0.005 \\
\hline Net protein oxidation, NPO, $\mathrm{kcal} / \mathrm{kg} \mathrm{LBM} / d$ & $9.7 \pm 1.1$ & $5.7 \pm 0.6$ & 0.005 \\
\hline Net protein oxidation, NPO, $\mathrm{kcal} / \mathrm{kg} \mathrm{TBF} / \mathrm{d}$ & $12.7 \pm 1.5$ & $29.1 \pm 2.4$ & 0.001 \\
\hline 7. Plasma glycerol, $\mu \mathrm{mol} / \mathrm{liter}$ & $69 \pm 11$ & $103 \pm 9$ & 0.05 \\
\hline 8. Glycerol turnover, $\mu \mathrm{mol} / \mathrm{min}$ & $236 \pm 40$ & $292 \pm 44$ & - \\
\hline Glycerol turnover, $\mu \mathrm{mol} / \mathrm{kg} \mathrm{LBM} / \mathrm{min}$ & $4.0 \pm 0.6$ & $4.5 \pm 0.6$ & - \\
\hline Glycerol turnover, $\mu \mathrm{mol} / \mathrm{kg} \mathrm{TBF} / \mathrm{min}$ & $5.2 \pm 0.8$ & $22.8 \pm 3.1$ & 0.001 \\
\hline 9. Glycerol clearance, liter/min & $3.4 \pm 0.5$ & $2.7 \pm 0.4$ & - \\
\hline 10. Whole body lipolysis rate, WBLR, $k c a l / d^{*}$ & $2,764 \pm 465$ & $3,424 \pm 552$ & - \\
\hline Whole body lipolysis rate, WBLR, $\mathrm{kcal} / \mathrm{kg} \mathrm{LBM} / \mathrm{d}$ & $47.2 \pm 7.5$ & $52.7 \pm 8.5$ & - \\
\hline Whole body lipolysis rate, WBLR, $\mathrm{kcal} / \mathrm{kg} \mathrm{TBF} / \mathrm{d}$ & $61.4 \pm 10.3$ & $268 \pm 43$ & 0.005 \\
\hline 11. \% Mobilized fat oxidized, NFO/WBLR, $\%$ & $36.1 \pm 5.3$ & $46.8 \pm 6.4$ & - \\
\hline 12. TG recycling, WBLR-NFO, $\mathrm{kcal} / \mathrm{d}$ & $1,767 \pm 283$ & $1,891 \pm 454$ & - \\
\hline TG recycling, WBLR-NFO, $\mathrm{kcal} / \mathrm{kg} \mathrm{LBM} / \mathrm{d}$ & $30.2 \pm 4.8$ & $29.1 \pm 7.0$ & - \\
\hline TG recycling, WBLR-NFO, $k \mathrm{cal} / \mathrm{kg}$ TBF/d & $39.4 \pm 6.3$ & $147.7 \pm 35.5$ & 0.025 \\
\hline 13. Energy cost of TG-FFA cycle, $\mathrm{kcal} / \mathrm{d}^{\ddagger}$ & $33 \pm 7$ & $35 \pm 9$ & - \\
\hline
\end{tabular}

Mean \pm SEM.

${ }^{*}$ Mol wt of TG $=859.5 ; 8,143 \mathrm{kcal} / \mathrm{mol} \mathrm{TG} .{ }^{\ddagger} 8$ ATP for each mol of TG recycled; energy equivalent to $1 \mathrm{~mol}$ of ATP $=19.05 \mathrm{kcal}$.

body weight at a slower relative rate than the nonobese (29). On the other hand, trauma elicits in obese patients an enhanced protein breakdown resulting in an increased nitrogen loss compared with equally injured nonobese patients. An analysis of the change in total body nitrogen during fasting shows that body $\mathrm{N}$ exists in two pool groups, a small one with a rapid turnover rate and a large one that turns over more slowly (29). The former may correspond to "labile proteins" (30) and its pool size is larger ( $6 \%$ of body $N$ ) in obese (29) than in the nonobese ( $1 \%$ of body $N$ ). It appears that trauma and confinement to bed enhances the mobilization of the labile protein pool in obese victims.

One of the best estimates of skeletal-muscle catabolism that allows calculation of the rate of muscle-protein breakdown is the urinary excretion of $3 \mathrm{MH}(31-34)$. This estimate becomes possible mainly because of the nonreusable, nondegradative, and nonconjugative nature in humans of the liberated $3 \mathrm{MH}$ from proteolysis. The linear relationship demonstrated between urinary $3 \mathrm{MH}$ excretion and whole-body breakdown rate in normal and depleted patients (33) is also seen in our trauma victims (Fig. 2). Using the relationship of $4.2 \mu \mathrm{mol}$ $3 \mathrm{MH}$ per gram of mixed muscle protein in humans (34), it can be calculated that 156 and $113 \mathrm{~g}$ muscle protein are degraded per day in obese and nonobese patients, respectively. This corresponds to $46 \%$ and $41 \%$ of the whole-body protein breakdown in agreement with $39 \%$ reported by Long et al. (31). The amount of muscle protein broken per gram of muscle mass per day is $0.0042 \mathrm{~g}$ in obese patients compared with $0.0039 \mathrm{~g}$ in nonobese patients. Thus the results suggest that although the rate of muscle breakdown per unit muscle mass is almost the same in the two groups, it is the greater muscle mass of the obese group that primarily accounts for the higher rate of overall breakdown rate. Consequently, in absolute terms and as a fraction of the body protein, the obese patients mobilize more nitrogen than the nonobese.

PSE is significantly low in trauma compared with other pathological states (15). The driving force for the breakdown of proteins in acute injury seems to result from the relative demand for amino acids to synthesize glucose or new proteins. In trauma patients more proteins are degraded than are needed to synthesize new proteins, with the additional breakdown products being used for increased glucose synthesis (15). Obese trauma victims show a significantly decreased PSE compared with equally injured nonobese individuals. It seems that a rela- 


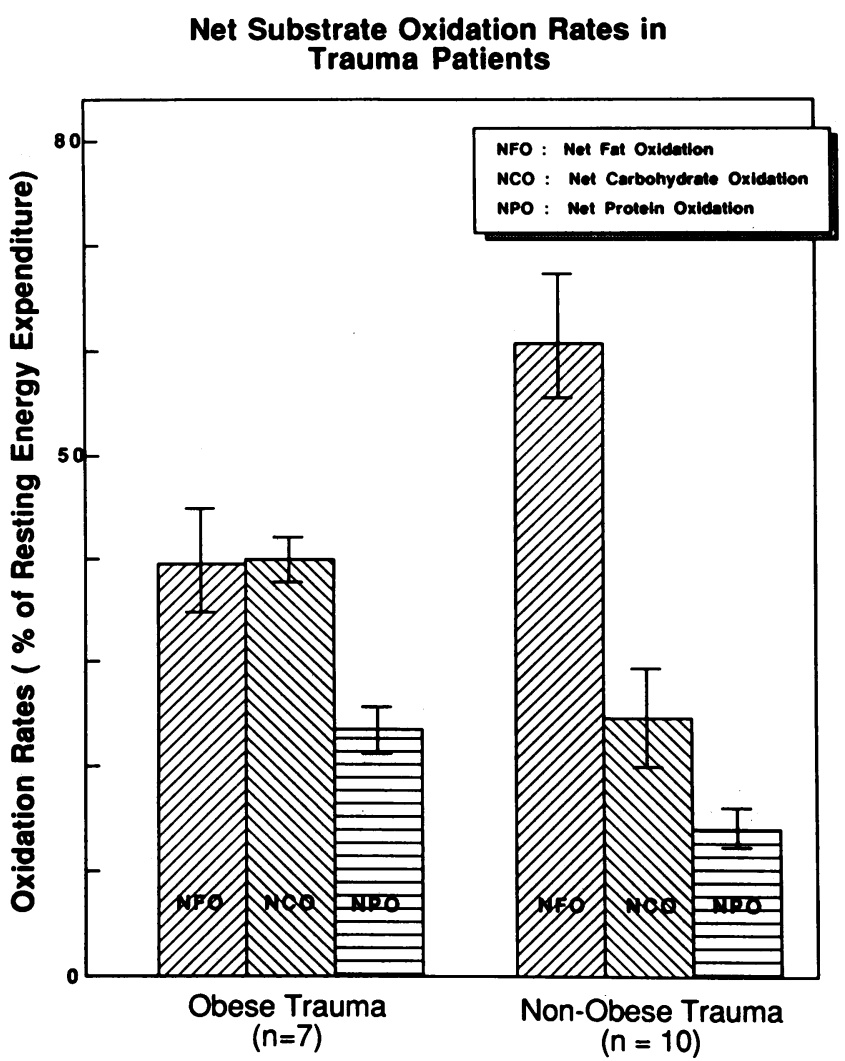

Figure 3. Whole-body net oxidation rates (as percentage of resting energy expenditure) of NFO, NCO, and NPO in obese $(n=7)$ and nonobese $(n=10)$ trauma patients. $P=0.01$ for NFO; $P=0.05$ for NCO; $P=0.025$ for NPO (obese vs. nonobese trauma).

tive block in lipid mobilization and oxidation in obese patients results in a shift to the preferential use of carbohydrate calories that accelerates the increased breakdown of body proteins at this acute stage of injury.

Healthy obese subjects have an increased (24\%) REE compared with nonobese subjects and LBM largely accounts for

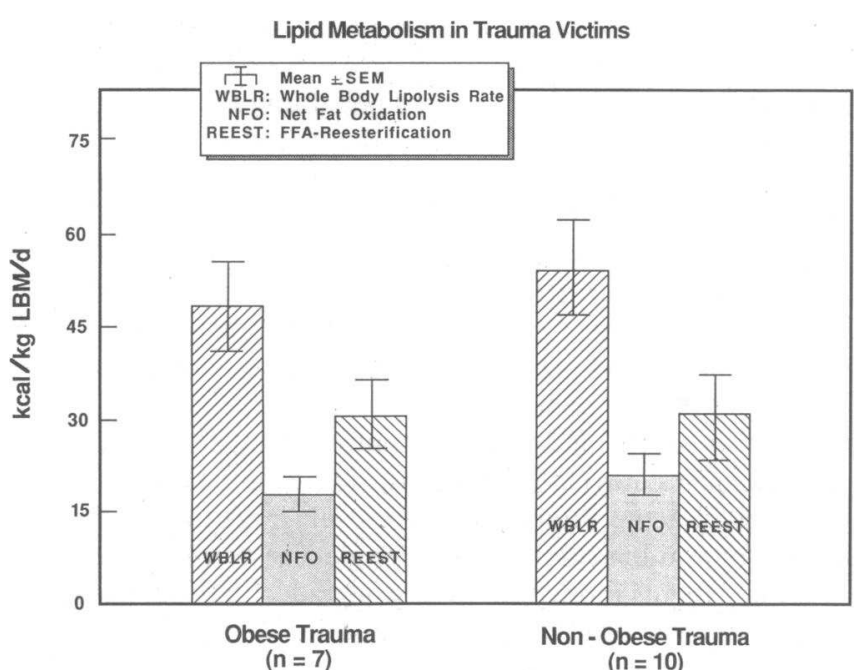

Figure 4. Whole-body lipolysis rate and its partition between NFO and FFA reesterification in obese and nonobese trauma patients. this higher REE (2). However, the REE of hypermetabolic, traumatized obese and nonobese patients are very similar, implying a somewhat blunted injury response in obese subjects. This trend is also seen in oxygen consumption. There is a significant change in the use of the primary fuel sources. Under stress conditions obese patients could not take advantage of their most abundant fat fuel sources but have to depend on the effcient use of endogenous glucose synthesized from the breakdown products of body protein. The mechanism responsible for this blunted lipolytic response in subjects with increased adiposity is not known. Body composition contributes to the regulation of lipolysis during fasting and the decreased rate of lipolysis in subjects who have excess fat may reflect the decreased need per unit fat mass for lipolysis to meet the energy requirements of the lean body mass (25).

Compared with 87-h fasted normal weight subjects, fasting normal, obese subjects have similar plasma glycerol levels and turnover rates but increased plasma glucose, FFA, insulin, epinephrine, and norepinephrine concentration (25). Similar trends are seen in trauma victims except in plasma glycerol and catecholamine levels. In obese trauma victims the lower plasma glycerol level is due to a sustained lipolysis and an increased clearance perhaps for gluconeogenesis. Glycerol oxidation rate as well as the percentage of glycerol converted to glucose is higher in normal obese subjects compared with lean (35). The elevated levels of plasma FFA in obese trauma patients may be due to the decreased fractional clearance rate as seen in normal obese which is not stimulated by glucose to the same extent as in lean subjects (36). The release of endogenous catecholamines during fasting is one of the important factors regulating the mobilization of fatty acids from adipose tissue. Fasting stimulates the adrenal medulla and increases the concentration of circulating epinephrine. The threshold range of $75-125 \mathrm{pg} / \mathrm{ml}$ of plasma epinephrine for its lipolytic and hemodynamic effects (37) is far exceeded in traumatized obese $(261 \pm 86 \mathrm{pg} / \mathrm{ml})$ as well as nonobese $(368 \pm 79)$ patients. Plasma concentrations of norepinephrine also are higher in fasted nonobese trauma patients than the obese. Compared with the plasma levels reported in uninjured fasting obese and nonobese subjects (25), the epinephrine levels are increased due to trauma five times in nonobese patients compared with two times in obese patients. This indicates the relatively blunted stimulation of lipolysis in obese trauma subjects just as observed in unstressed, short-term fasting obese subjects (24). Similar blunted lipolytic effects in obese patients were also seen in intense exercise-induced stress (38). It is also possible that other mechanisms such as receptor downregulation or desensitization may be at work in mediating the decreased lipolysis and fat oxidation in the obese trauma victims. A decreased activation of the hormone-sensitive lipase complex appears to be the mechanism underlying a blunted lipolytic response of fat cells to catecholamine stimulation in elderly subjects with more body fat (39) and this mechanism may also be active in obese subjects.

Most obese patients are hyperinsulinemic and have some peripheral insulin resistance. Acute injury also provokes further insulin resistance. Hypersecretion of insulin has been considered as one of the main causes of hyperinsulinemia. A more reliable index of beta cell function and insulin secretion rate is the C-peptide concentration in blood rather than insulin level (40). Traumatized obese patients have a significantly higher level of plasma $\mathrm{C}$-peptide indicating a higher production rate of 
insulin. This higher production of insulin may in itself have an inhibitory effect on fat mobilization. It is worthwhile to measure the growth hormone levels in the catabolic phase of traumatized obese patients and to investigate the efficacy of adjuvant growth hormone treatment in mobilizing the fat stores and to conserve body protein.

Nutritional management of hospitalized critically ill obese patients with excess adiposity represents a challenge to practitioners of specialized nutritional support (41). This study emphasizes that many complex factors should be taken into consideration, including the hypersecretion of insulin, increased proteolysis and enhanced loss of $\mathrm{N}$, resistance to lipolysis and fat oxidation, and the seeming preference for increased carbohydrate utilization. It should aim at adequate feedings to be effective in preserving the functional lean body mass and in efficient mobilization of fat fuel resources.

\section{Acknowledgments}

This work was supported in part by the Arizona Disease Control Research Commission grant 82-9286.

\section{References}

1. Bray, G. A. 1976. The Obese Patient. W. B. Saunders Co., Philadelphia, PA

2. Ravussin, E. B., B. Burnard, Y. Schutz, and E. Jequier. 1982. 24 hr. energy expenditure and resting metabolic rate in obese, moderately obese and control subjects. Am. J. Clin. Nutr. 35:566-573.

3. Sims, S. A., and E. S. Horton. 1968. Endocrine and metabolic adaptation to obesity and starvation. Am. J. Clin. Nutr. 21:1455-1470.

4. Zuniga-Guajardo, S., J. Jimenez, A. Angel, and B. Zinman. 1986. Effects of massive obesity on insulin sensitivity and insulin clearance and the metabolic response to insulin as assessed by the euglycemic clamp technique. Metab. Clin. Exp. 35:278-282.

5. Strauss, R. J., and L. Wise. 1978. Operative risks of obesity. Surg. Gynecol. \& Obstet. 146:286-291.

6. Surin, V. V., and K. Sundholm. 1983. Survival of patients and prosthesis after total hip arthroplastics. Clin. Orthop. Relat. Res. 177:148-153.

7. Pasulka, P. S., B. R. Bistrian, P. N. Benotti, and G. L. Blackburn. 1986. The risks of surgery in obese patients. Ann. Intern. Med. 104:540-546.

8. Baker, S. P., B. O'Neill, W. Hadden, Jr., and W. B. Long. 1974. The injury severity score: a method for describing patients with multiple injuries and evaluating emergency care. J. Trauma. 14:187-196.

9. Weir, J. B. 1949. New methods for calculating metabolic rate with special reference to protein metabolism. J. Physiol. (Lond.). 109:1-9.

10. Frayn, K. N. 1983. Calculation of substrate oxidation rates in vivo from gaseous exchange. J. Appl. Physiol. 55:628-634.

11. Harris, J. A., and F. G. Benedict. 1919. Biometric studies of basal metabolism in man. Carnegie Institute of Washington, DC. Pub. No. 279.

12. Carpentier, Y. A., M. Jeevanandam, A. P. Robin, J. Nordenstrom, R. E. Burr, R. L. Liebel, J. Hirsch, D. H. Elwyn, and J. M. Kinney. 1984. Measurement of glycerol turnover by infusion of non-isotope glycerol in normal and injured subjects. Am. J. Physiol. 247:E405-E411.

13. Elia, M., C. Zed, G. Neale, and G. Livesey. 1987. The energy cost of triglyceride fatty acid recycling in non-obese subjects after an overnight fast and four days of starvation. Metab. Clin. Exp. 36:251-255.

14. Jeevanandam, M., M. F. Brennan, G. D. Horowitz, D. Rose, M. H. Mihranian, J. Daly, and S. F. Lowry. 1985. Tracer priming in human protein turnover studies with ${ }^{15} \mathrm{~N}$ glycine. Biochem. Med. 34:214-225.

15. Jeevanandam, M., D. H. Young, and W. R. Schiller. 1989. Endogenous protein synthesis efficiency in trauma victims. Metab. Clin. Exp. 38:967-973.

16. Carpentier, Y. A., J. Askanazi, D. H. Elwyn, M. Jeevanandam, F. E. Gump, A. I. Hyman, R. Burr, and J. M. Kinney. 1979. Effect of hypercaloric glucose infusion in lipid metabolism in injury and sepsis. J. Trauma. 19:649-654.
17. Livesey, G. 1984. The energy equivalent of ATP and the energy values of food proteins and fat. Br. J. Nutr. 51:15-28.

18. Waterlow, J. C., P. J. Garlick, and D. J. Millward, editors. 1978. Protein Turnover in Mammalian Tissues and in the Whole Body. North-Holland Publishing Co., Amsterdam.

19. Waterlow, J. C. 1984. Protein turnover with special reference to man. $Q$. $J$. Exp. Physiol. 69:409-438.

20. Fern, E. B., P. J. Garlick, M. A. McNurlan, and J. C. Waterlow. 1981. The excretion of isotope in urea and ammonia for estimating protein turnover in man with ${ }^{15} \mathrm{~N}$ glycine. Clin. Sci. (Lond.). 61:217-228.

21. Fern, E. B., P. J. Garlick, and J. C. Waterlow. 1985. Apparent compartmentalization of body proteins in one human subject: its consequence in measuring the rate of whole-body protein synthesis with ${ }^{15}$ N. Clin. Sci. (Lond.). 68:271282.

22. Galloway, D. H., A. C. F. Odell, and S. Margen. 1978. Sweat and miscellaneous nitrogen losses in human balance studies. J. Nutr. 101:775-786.

23. Snedecor, G. W., and W. G. Cochran. 1971. Statistical Methods. 7th ed. Iowa State University Press, Ames, IA.

24. Wolfe, R. R., E. J. Peters, S. Klein, O. B. Holland, J. Rosenblatt, and H. Gary, Jr. 1987. Effect of short-term fasting on lipolytic responsiveness in normal and obese subjects. Am. J. Physiol. 252:E189-E196.

25. Klein, S., V. R. Young, G. L. Blackburn, B. R. Bistrian, and R. R. Wolfe. 1988. The impact of body composition on the regulation of lipolysis during short-term fasting. J. Am. Coll. Nutr. 7:77-84.

26. Fleck, A. 1976. Injury and plasma proteins. In Metabolism and Response to Injury. A. W. Wilkinson and D. P. Cuthbertson, editors. Pitman Medical, London. 229-236.

27. Davis, J. W. L., S.-O. Liljedahl, and P. Reinzenstein. 1969. Metabolic studies with labeled albumin in patients with paraplegia and other injuries. Injury. 1:273-280.

28. Schiller, W. R., C. L. Long, and W. S. Blakemore. 1979. Creatinine and nitrogen excretion in seriously ill and injured patients. Surg. Gynecol. \& Obstet. 149:561-566.

29. Forbes, G. B., and E. J. Drenick. 1979. Loss of body nitrogen on fasting. Am. J. Clin. Nutr. 32:1570-1574.

30. Allison, J. B., and R. W. Wannemacher. 1965. The conceptual significance of labile and over-all protein reserves of the body. Am. J. Clin. Nutr. 16:445-451.

31. Long, C. L., R. H. Birkhahn, J. W. Geiger, J. E. Betts, W. R. Schiller, and W. S. Blakemore. 1981. Urinary 3 methylhistidine: an assessment of muscle protein catabolism in adult normal subjects and during malnutrition, sepsis and skeletal trauma. Metab. Clin. Exp. 30:765-776.

32. Ballard, F. J., and F. M. Tomas. 1983. 3 methylhistidine as a measure of skeletal muscle protein breakdown in human subjects: the case for its continuous use. Clin. Sci. (Lond.). 65:209-215.

33. Lowry, S. F., G. D. Horowitz, M. Jeevanandam, A. Legaspi, and M. F. Brennan. 1985. Whole body protein breakdown and 3 methylhistidine excretion during brief fasting, starvation and intravenous repletion in man. Ann. Surg 202:21-27.

34. Bilmazes, C., R. Uauy, L. N. Haverberg, H. N. Munro, and V. R. Young. 1978. Muscle protein breakdown rates in humans based on 3 methylhistidine content of mixed muscle proteins in skeletal muscle and urinary output of 3 methylhistidine. Metab. Clin. Exp. 27:525-530.

35. Bortz, W. M., P. Paul, A. C. Haff, and W. L. Holmes. 1972. Glycerol turnover and oxidation in man. J. Clin. Invest. 51:1537-1546.

36. Nestel, P., T. Ishikawa, and R. B. Goldrick. 1978. Diminished plasma free fatty acid clearance in obese subjects. Metab. Clin. Exp. 27:589-597.

37. Galster, A. D., W. E. Clutter, P. E. Cryer, J. A. Collins, and D. M. Bier. 1981. Epinephrine plasma thresholds for lipolytic effects in man: Measurements of fatty acid transport with $\left[1-{ }^{13} \mathrm{C}\right]$ palmitic acid. J. Clin. Invest. 67:1729-1738.

38. Yale, J. R., L. A. Leiter, and E. B. Marliss. 1989. Metabolic responses to intense exercise in lean and obese subjects. J. Clin. Endocrinol. \& Metab. 68:438445.

39. Lonnqvist, F., B. Nyberg, H. Wahrenberg, and P. Arner. 1990. Catecholamine-induced lipolysis in adipose tissue of the elderly. J. Clin. Invest. 85:1614 1621 .

40. Faber, O. K., C. Hagen, C. Binder, J. Markussen, V. K. Naithani, P. M. Blix, H. Kuzuyu, D. L. Horwitz, A. H. Rubenstein, and N. Rossing. 1978. Kinetics of human connecting peptide in normal and diabetic subjects. J. Clin. Invest. 62:197-203.

41. Pasulka, P. S., and D. Kohl. 1989. Nutrition support of the stressed obese patient. Nutr. Clin. Pract. 4:130-132. 